\title{
The clinical significance of $\mathbf{c}$-Kit mutations in metastatic oral mucosal melanoma in China
}

\author{
Xuhui Ma ${ }^{1, *}$, Yunteng $\mathrm{Wu}^{1, *}$, Tian Zhang ${ }^{1}$, Hao Song ${ }^{1}$, Houyu $\mathrm{Jv}^{1}$, Wei Guo ${ }^{1}$ and \\ Guoxin Ren ${ }^{1}$ \\ ${ }^{1}$ Department of Oral and Maxillofacial-Head and Neck Oncology, Shanghai Ninth People's Hospital, School of Medicine, \\ Shanghai Jiaotong University, Shanghai 200011, China \\ * These authors have contributed equally to this work \\ Correspondence to: Wei Guo, email: guoweicn@yahoo.com \\ Guoxin Ren, email: renguoxincn@hotmail.com
}

Keywords: oral mucosal melanomas, distal metastasis, c-Kit, c-Kit mutation, imatinib

Abbreviations: OMMs, oral mucosal melanomas; OS, overall survival; CLN, cervical lymph node; ECOG, Eastern Cooperative Oncology Group.

Received: March 13, $2017 \quad$ Accepted: June 20, $2017 \quad$ Published: July 31, 2017

Copyright: Ma et al. This is an open-access article distributed under the terms of the Creative Commons Attribution License 3.0 (CC BY 3.0), which permits unrestricted use, distribution, and reproduction in any medium, provided the original author and source are credited.

\section{ABSTRACT}

c-Kit mutations are frequently detected in mucosal melanomas, but their clinical significance in metastatic oral mucosal melanomas (OMM) remains unclear. The main purpose of this study was to investigate the clinical and pathological features of metastatic OMMs with c-Kit mutations and the efficiency of the tyrosine kinase inhibitor imatinib in treating metastatic OMMs. We found thatresidual primary lesion and neck lymph nodes could act as independent prognostic factors in metastatic OMM patients. c-Kit mutations were detected in 22 out of $139(15.8 \%)$ metastatic OMM patients. Under chemotherapy, the overall survival (OS) of c-Kit mutant patients was significantly shorter than that of wild-type patients. The Ki67 expression was significantly higher in c-Kit mutant patients than in wild-type patients. In distant metastatic OMM patients with c-Kit mutations, the treatment with c-Kit inhibitor resulted in a better OS. In conclusion, residual primary lesion, cervical lymph nodes and c-Kit mutations act as adverse prognostic factors of metastatic OMMs. The Kit inhibitor imatinib could benefit metastatic OMM patients with c-Kit mutations.

\section{INTRODUCTION}

Melanoma is a highly aggressive malignant tumor with biologically distinct subtypes $[1,2]$. Oral mucosal melanoma (OMM) is an exceedingly rare neoplasm [3-5], accounting for less than $1 \%$ of all melanomas in the USA and about $7.5 \%$ in Asians $[6,7]$. The dismal prognosis of melanoma results mainly from distant metastasis, and the median overall survival (OS) is less than 10 months in advanced patients [8-10]. More ominously, some traditional cytotoxic chemotherapeutic agents, including dacarbazine and temozolomide, have been reported to be ineffective against metastatic OMMs [11-14]. Clearly, there is a need to find a more effective treatment for metastatic OMMs.
Some genetic mutations, such as active mutations of Braf and c-Kit, may act as molecular hubs promoting the development of melanomas and thus can be potential therapeutic targets [15]. Small molecule inhibitors of both Braf (Dabrafenib) and c-Kit (Imatinib) have shown promising results for advanced cutaneous melanoma patients. In comparison with cutaneous melanoma that has a high rate of Braf mutations, OMM rarely harbors Braf mutations [16-18], which hampered the use of Braf inhibitors in OMM patients. In addition, there is increasing evidence that OMM harbors $c$-Kit mutations [19-21], indicating that imatinib, a c-Kit inhibitor, may be beneficial for advanced OMM patients.

The $c$-Kit gene encodes CD117, a type III transmembrane receptor tyrosine $[22,23]$. $c$-Kit protein 
(Kit) includes five distinct domains: a glycosylated extracellular ligand binding domain (coded by exons 1-9), a hydrophobic transmembrane domain (coded by exon 10), an intracellular juxtamembrane domain (coded by exon 11), and two tyrosine kinase domains (coded by exons 12-21) [24]. The intracellular juxtamembrane domain has been shown to be autoinhibitory, which can prevent Kit activation in the absence of extracellular ligand. As the ligand such as stem cell factor binds to the extracellular domain, the Kit receptors dimerize to each other, resulting in autophosphorylation of the tyrosine kinase domains and activation [23]. Once activated, Kit can initiate the activation of a variety of downstream pathways including the MAPK/MEK and PI3K/AKT pathways which play important roles in cancer development [23, 25].

Activating $c$-Kit mutations in the juxtamembrane and other domains has been considered as an oncogene and also a therapeutic target in various tumors [23]. $c$-Kit mutation has been detected in various mucosal melanomas $[19,20]$, but it remains unclear whether it is a prognostic factor or therapeutic target in distant metastatic OMMs. The main purpose of this study was to investigate the clinical and pathological features of metastatic OMMs with $c$-Kit mutations and the efficiency of the tyrosine kinase inhibitor imatinib in treating metastatic OMMs. In doing so, we investigated the clinical manifestations, histopathology, treatment, and outcomes of metastatic OMM patients, aiming to explore the prognostic factors of metastatic OMMs and the efficacy of imatinib on metastatic OMMs with $c$-Kit mutations.

\section{RESULTS}

\section{Patient characteristics}

A total of 139 patients with distant metastases were enrolled in this study, including 75 males (53.96\%) and 64 females (46.04\%). The median age of these patients at first metastasis was 61 years (19-75 years). The primary lesion was located in the hard palate in 85 patients $(61.15 \%$; Supplementary Figure 1A), maxillary gum in 28 patients (20.14\%; Supplementary Figure 1B), mandible gum in 17 patients (12.23\%; Supplementary Figure 1C), and other sites such as buccal and tongue in 9 patients $(6.47 \%$; Supplementary Figure 1D), respectively. At the diagnosis of distant metastasis, 103 patients had metastases at only one site, and the rest 36 patients had metastases in two or more organs. Residual or recurrent lesions were detected in the oral cavity of 23 patients, while positive neck nodes were detected in 25 patients (Table 1). Of these 139 patients, $22(15.8 \%)$ harbored $c$-Kit mutations, including 9 $(40.9 \%)$ with mutations in exon $11,5(22.7 \%)$ in exon 13 , $3(13.6 \%)$ in exon 18,2 in exon $17(9.1 \%)$ and $9(9.1 \%)$, and $1(4.5 \%)$ in both exon 13 and exon 9 , respectively (Table 2).

\section{Primary lesion and positive cervical lymph node (CLN) were significant prognostic factors for distant metastatic OMMs}

Figure 1A showed that patients with residual primary lesion had worse outcomes than those without residual primary lesion, with a median OS of 26 and 35 weeks, respectively $(P<0.001)$. Figure $1 \mathrm{~B}$ showed that patients with positive CLNs had worse outcomes than those with negative CLNs, with a median OS of 27 and 35 weeks, respectively $(P<0.001)$. Multivariate analysis suggested that both primary lesion and positive neck nodes could act as an independent prognostic factor for distant metastatic OMMs (Table 1).

\section{Multiple distant lesions resulted in worse outcome than a single distant lesion}

Nearly $3 / 4$ patients had only one distant lesion, and, as a consequence, they had a longer median OS (33 weeks) than patients with multiple distant lesions (31 weeks) $(P=0.001$; Figure 1C). However, this variable was not an independent prognostic factor in the multivariate analysis (Table 1).

\section{c-Kit mutation was an adverse prognostic factor for distant metastatic OMMs}

It has been recently reported that $c$-Kit mutation may be a negative prognostic factor in melanoma [26], but it remains unknown whether it could affect the OS of metastatic OMMs patients. In this study, we found no significant difference in OS between WT and c-Kit mutant patients (Table 1 and Figure 2A). However, as such findings could be confounded by different treatment strategies received by $c$-Kit mutant patients, we divided patients into 3 subgroups depending on their status of $c$-Kit mutation and treatment: wild-type patients (Group 1, $n=117$ ), patients with $c$-Kit mutations and chemotherapy (Group 2, $n=10$ ), and patients with $c$-Kit mutations and imatinib treatment (Group $3, n=12$ ). There was no significant difference in patient characteristics, including CLN, the status of primary lesion, and the sites of distant metastases, among the three groups (Table 3 ). However, we found that the median OS of Group 2 was significantly shorter than that of Group 1 (28 VS 32 weeks, $P=0.032$; Table 4 and Figure 2B), thus indicating a poorer prognosis in patients with $c$-Kit mutations. Multivariate Cox regression analysis suggested that $c$-Kit mutation could act as an independent prognostic factor (Table 4). Interestingly, we found that all patients with mutations in exon 11 and 13 had an OS of less than 30 weeks, which showed a decreasing tendency in comparison with patients with mutations in other exons, although without statistical significance probably because of the small sample size. All these results indicated that 
Table 1: OS of metastatic OMMs patients by prognostic variables

\begin{tabular}{|c|c|c|c|c|}
\hline \multirow{2}{*}{ Variable } & \multirow{2}{*}{ NO. } & \multirow{2}{*}{$\begin{array}{c}\text { MedinaOS } \\
\text { (weeks) }\end{array}$} & \multicolumn{2}{|c|}{$P$} \\
\hline & & & Unviariate & Multivariate \\
\hline \multicolumn{5}{|l|}{ Sex } \\
\hline Male & 75 & 32 & \multirow{2}{*}{0.665} & - \\
\hline Female & 64 & 32 & & \\
\hline \multicolumn{5}{|l|}{ Age, years } \\
\hline$<60$ & 61 & 32 & \multirow{2}{*}{0.708} & - \\
\hline$\geq 60$ & 78 & 33 & & \\
\hline \multicolumn{5}{|l|}{ Primary site } \\
\hline Palate & 85 & 32 & \multirow{4}{*}{0.857} & - \\
\hline Maxillary gum & 28 & 34 & & \\
\hline Mandible gum & 17 & 33 & & \\
\hline Other site & 9 & 35 & & \\
\hline \multicolumn{5}{|l|}{ ECOG PS score } \\
\hline 0 & 47 & 31 & \multirow{2}{*}{0.206} & - \\
\hline 1 & 92 & 34 & & \\
\hline \multicolumn{5}{|l|}{ Primary lesion } \\
\hline Positive & 23 & 26 & \multirow{2}{*}{$<0.001$} & $<0.001$ \\
\hline Negative & 116 & 35 & & \\
\hline \multicolumn{5}{|l|}{ CLN } \\
\hline Positive & 25 & 27 & \multirow{2}{*}{$<0.001$} & $<0.001$ \\
\hline Negative & 114 & 35 & & \\
\hline \multicolumn{5}{|l|}{$c$-Kit mutation } \\
\hline Positive (Group 2+3) & 22 & 32 & \multirow{2}{*}{0.583} & - \\
\hline Negative (Group 1) & 117 & 32 & & \\
\hline \multicolumn{5}{|l|}{ Site of metastases } \\
\hline Single site & 103 & 33 & \multirow{2}{*}{0.001} & 0.077 \\
\hline Multiple sites & 36 & 31 & & \\
\hline
\end{tabular}

c-Kit mutation may act as an adverse prognostic factor for distant metastatic OMMs.

The proliferation rate can greatly impact OS in some tumors, and thus the expression of Ki67, the biomarker of proliferation marker, may act as an independent prognostic factor in melanoma [27]. Kit signaling is critical for the proliferation of various cell types including melanoma cells $[16,23,28]$. Thus, we suspected that $c$-Kit mutations could impact the OS of metastatic OMM patients through cell proliferation. As it was impossible to obtain metastatic tumor tissues, we examined cell proliferation rate in the primary melanoma by evaluating the expression of Ki67 using immunohistochemistry (Figure 3A). As shown in Figure 3B-3D, there were more Ki67 positive cells in $c$-Kit mutant patients than in WT patients $(P<0.001)$. These results supported our hypothesis that $c$-Kit mutations could promote cell proliferation in OMMs, thus contributing to the decreased OS.

\section{Imatinib may benefit metastatic OMM patients with $c$-Kit mutations}

To determine whether imatinib was beneficial for metastatic OMM patients with $c$-Kit mutations, we compared the OS of $c$-Kit mutant patients received conventional chemotherapy (Group 2) and imatinib treatment (Group 3). The baseline of these two groups was comparable (Table 3). Both Log-rank test and multivariate 
Table 2: Specific $c$-Kit mutations in each exon

\begin{tabular}{|c|c|c|c|c|c|c|c|}
\hline \multirow{2}{*}{ c-Kit mutation } & \multicolumn{3}{|c|}{ c-Kit mutant with chemo $(\mathrm{n}=10)$} & \multicolumn{3}{|c|}{$c$-Kit mutant with imatinib $(\mathrm{n}=12)$} & \multirow{2}{*}{$\frac{\text { Total }(\mathrm{n}=22)}{\operatorname{No}(\%)}$} \\
\hline & No. (\%) & mutation & No. & No. $(\%)$ & mutation & No. & \\
\hline \multirow[t]{2}{*}{ Exon 9} & $1(10)$ & & & $1(8.3)$ & & & $2(9.1)$ \\
\hline & & F504L & 1 & & F504L & 1 & \\
\hline \multirow[t]{4}{*}{ Exon 11} & $4(40)$ & & & $5(41.7)$ & & & $9(40.9)$ \\
\hline & & L576P & 3 & & L576P & 4 & \\
\hline & & V559A & 1 & & V559A & 0 & \\
\hline & & - & - & & V560D & 1 & \\
\hline \multirow[t]{2}{*}{ Exon 13} & $2(20)$ & & & $3(25)$ & & & $5(22.7)$ \\
\hline & & K642E & 2 & & K642E & 3 & \\
\hline \multirow[t]{3}{*}{ Exon 17} & $2(20)$ & & & $0(0)$ & & 0 & $2(9.1)$ \\
\hline & & $\mathrm{D} 816 \mathrm{H}$ & 1 & & - & & \\
\hline & & N822I & 1 & & & & \\
\hline \multirow[t]{2}{*}{ Exon 18} & $1(10)$ & & & $2(16.7)$ & & & $3(13.6)$ \\
\hline & & A829P & 1 & & A829P & 2 & \\
\hline \multirow[t]{2}{*}{$\begin{array}{l}\text { Multiple } \\
\text { mutations }\end{array}$} & $0(0)$ & & & $1(8.3)$ & & & $1(4.5)$ \\
\hline & & - & - & & $\begin{array}{c}\text { F504L }(\text { Exon } \\
9)+\mathrm{K} 642 \mathrm{E}(\text { Exon } 13)\end{array}$ & 1 & \\
\hline
\end{tabular}

Cox regression analysis indicated that patients in Group 3 tended to have better clinical outcomes than patients in Group 2 (Table 5 and Figure 4A). It was interesting that in Group 3, patients with mutations in exon 11 and 13 showed a prolonged, albeit not significant, OS in comparison with patients with other mutations. This could be a true lack of difference or could be attributed to the limited sample size. All these results indicated that imatinib could prolong the OS of metastatic OMM patients with $c$-Kit mutations.

\section{Drug-resistance reduced the efficacy of imatinib in treating metastatic OMM patients with $c$-Kit mutation}

It was interesting that although the media OS of Group 1 was longer than Group 3, there was no significant difference in OS between Group 1 and Group $3(P=$ 0.065 ; Figure $4 \mathrm{~B}$ ), which could be attributed to treatment failure of imatinib due to drug resistance in some patients. We found that 5 out of 12 patients in Group 3 suffered from obvious drug resistance, including the enlarging of primary residual lesion, CLNs, distant metastases, and new sites of metastases during the imatinib treatment, and they died shortly after the occurrence of imatinib resistance. Thus, imatinib alone may not be a desirable treatment strategy for OMMs patients with $c$-Kit mutations.

\section{DISCUSSION}

More than $40 \%$ of OMM patients died of distant metastasis [8], and it remains a challenge to manage the life-threatening metastasis of OMMs [29, 30]. In this study, we retrospectively analyzed the clinical manifestations, histopathology, treatment strategies, and outcomes of 139 metastatic OMM patients hospitalized in a single institution from Jan. 2008 to Oct. 2015. In line with previous studies on OMMs [8,30], we also found that the most common site of the primary lesion was the hard palate $(61.15 \%)$, and that of distant metastasis was the lung (59.3\%). The median OS of metastatic OMM patients treated with chemotherapy was only 32 weeks, which was significantly shorter than that of cutaneous melanoma patients $[13,31]$.

In this study, we found that most metastatic OMM patients survived less than one year, which was shorter than that of cutaneous melanoma patients probably due to the heterogeneity of OMMs $[4,29]$. Both residual primary lesion and positive neck nodes may result in a decrease of OS in metastatic OMM patients and could act as independent prognostic factors. OMMs are difficult to completely remove due to the peculiar anatomic structure and function of the stomatognathic system and, as a consequence, residual primary lesion is inevitable in OMMs patients. The residual primary lesion and positive 

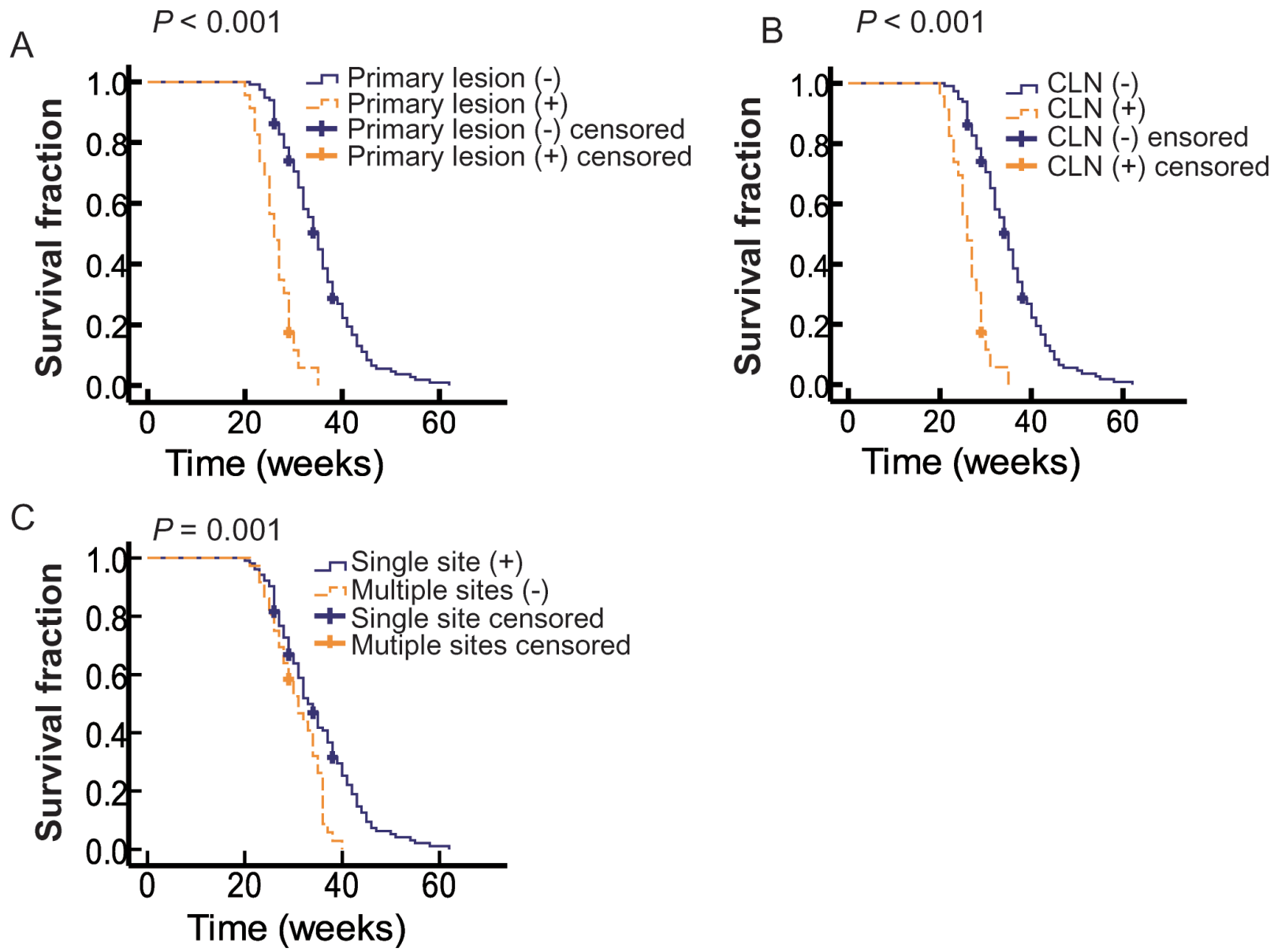

Figure 1: The correlation of OS with different clinical variables. (A) Kaplan-Meier curves showed the OS by residual primary lesion. Solid blue line indicates patients without primary lesion $(\mathrm{n}=116)$ and the dotted yellow line represents patients harbor primary lesion $(n=23)$. (B) Correlation of OS and cervical lymph node (CLN). Solid blue line indicates patients without CLN ( $\mathrm{n}=114)$ and the dotted yellow line represents patients with CLNs $(n=25)$. (C) Kaplan-Meier curves showed the OS by site of metastases. Solid blue line indicates patients with single site of metastases $(\mathrm{n}=103)$ and the dotted yellow line represents patients with multiple sites of metastases $(\mathrm{n}=36)$.
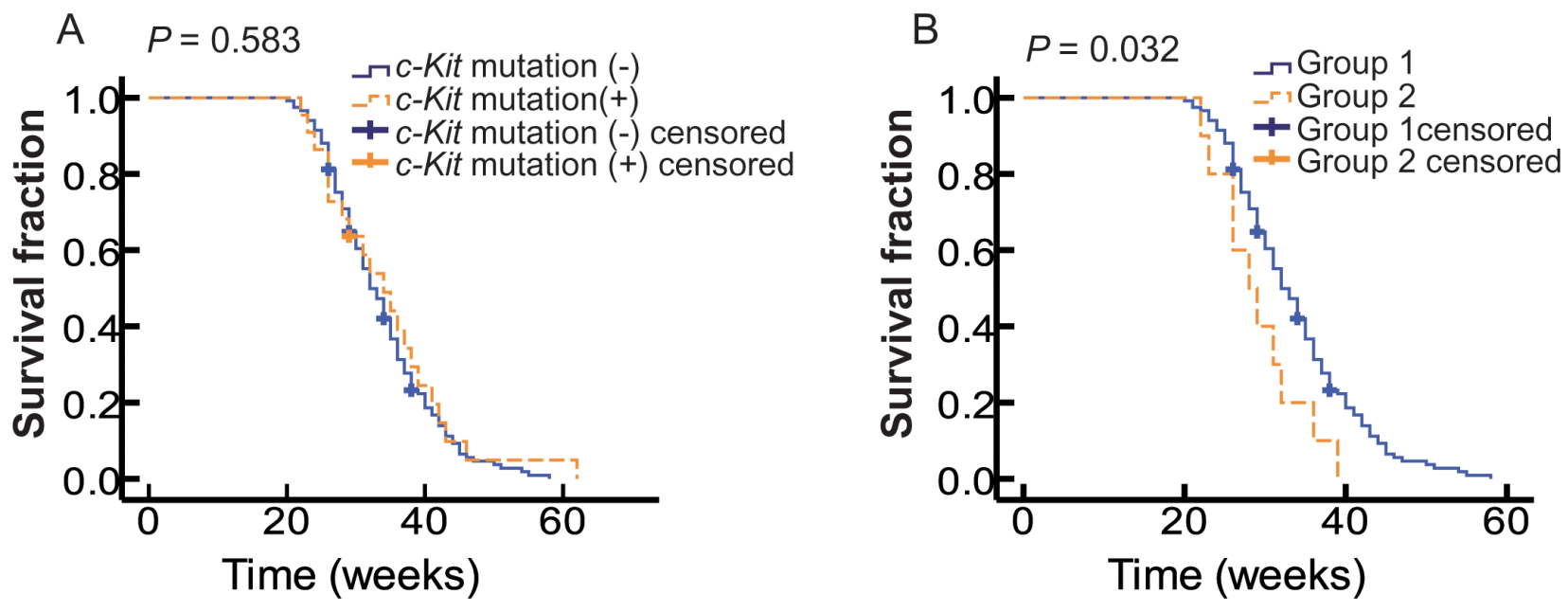

Figure 2: The correlation of OS with $\boldsymbol{c}$-Kit mutations. (A) Kaplan-Meier curves of OS of patients with WT $c$-Kit gene (solid blue line, $\mathrm{n}=117$ ) and mutant $c$-Kit gene (dotted yellow line, $\mathrm{n}=22$ ). (B) Kaplan-Meier curves of OS of patients received chemotherapy. Solid blue line indicates patients with WT $c$-Kit gene (Group1, n=117) and the dotted yellow line mutant $c$-Kit gene (Group2, n=10). 
Table 3: Clinical characteristics in WT and $c$-Kit mutant patients

\begin{tabular}{|c|c|c|c|c|c|c|c|c|c|}
\hline \multirow{2}{*}{ Characteristics } & \multicolumn{2}{|c|}{ Group $1(n=117)$} & \multicolumn{2}{|c|}{ Group $2(n=10)$} & \multicolumn{2}{|c|}{ Group $3(n=12)$} & \multicolumn{3}{|c|}{$P$} \\
\hline & No. & $\%$ & No. & $\%$ & No. & $\%$ & 1vs 2 & $2 v s 3$ & $1 \mathrm{vs} 3$ \\
\hline \multicolumn{10}{|l|}{ Sex } \\
\hline Male & 62 & 53.0 & 6 & 60.0 & 7 & 58.3 & \multirow{2}{*}{0.923} & \multirow{2}{*}{1.000} & \multirow{2}{*}{0.724} \\
\hline Female & 55 & 47.0 & 4 & 40.0 & 5 & 41.6 & & & \\
\hline \multicolumn{10}{|l|}{ Age, years } \\
\hline Median & $57.9 \pm 12.6$ & - & $59 \pm 12.5$ & - & $57.5 \pm 12.6$ & - & \multirow{2}{*}{0.798} & \multirow{2}{*}{0.783} & \multirow{2}{*}{0.798} \\
\hline Range & $19-75$ & & $35-74$ & & $28-72$ & & & & \\
\hline \multicolumn{10}{|l|}{ Primary site } \\
\hline Palate & 70 & 59.8 & 7 & 70.0 & 8 & 66.7 & \multirow{4}{*}{0.632} & \multirow{4}{*}{1.000} & \multirow{4}{*}{0.808} \\
\hline Maxillary gum & 25 & 21.4 & 1 & 10.0 & 2 & 16.7 & & & \\
\hline Mandible gum & 13 & 11.1 & 2 & 20.0 & 2 & 16.7 & & & \\
\hline Other site & 9 & 7.7 & 0 & 0.0 & 0 & 0.0 & & & \\
\hline \multicolumn{10}{|l|}{ ECOG PS score } \\
\hline 0 & 39 & 33.3 & 4 & 40.0 & 4 & 33.3 & \multirow{2}{*}{0.670} & \multirow{2}{*}{0.821} & \multirow{2}{*}{1.000} \\
\hline 1 & 78 & 66.7 & 6 & 60.0 & 8 & 66.7 & & & \\
\hline \multicolumn{10}{|l|}{ Primary lesion } \\
\hline Positive & 18 & 15.4 & 2 & 20.0 & 3 & 25.0 & \multirow{2}{*}{1.000} & \multirow{2}{*}{1.000} & \multirow{2}{*}{0.412} \\
\hline Negative & 99 & 84.6 & 8 & 80.0 & 9 & 75.0 & & & \\
\hline \multicolumn{10}{|l|}{ CLN } \\
\hline Positive & 21 & 18.0 & 2 & 20.0 & 2 & 16.7 & \multirow{2}{*}{1.000} & \multirow{2}{*}{1.000} & \multirow{2}{*}{1.000} \\
\hline Negative & 96 & 82.0 & 8 & 80.0 & 10 & 83.3 & & & \\
\hline \multicolumn{10}{|l|}{$\begin{array}{l}\text { Site of } \\
\text { metastases }\end{array}$} \\
\hline Single site & 87 & 74.4 & 7 & 70.0 & 9 & 75.0 & \multirow{2}{*}{1.000} & \multirow{2}{*}{1.000} & \\
\hline Multiple sites & 30 & 25.7 & 3 & 30.0 & 3 & 25.0 & & & 1.000 \\
\hline
\end{tabular}

neck nodes may cause a series of fatal complications, including bleeding and difficulty in feeding and breathing, which may result in poor prognosis and even death of these patients.

For many years, systemic chemotherapy has been the primary therapeutic option for patients with metastatic melanoma, but most often the outcomes are disappointing. Some somatic mutations occurring in melanomas, such as mutations in Braf and $c$-Kit, are considered as molecular targets for potential therapeutic intervention. Inhibitors of both Braf and c-Kit have been used in the treatment of various cancers, including some subtypes of melanoma [23]. Melanoma is a heterogeneous tumor, and mucosal melanoma differs from cutaneous melanoma in several physical, biological, and genetic characteristics [32]. Braf mutations were rare in OMMs, whereas $c$-Kit mutations were frequently detected in OMMs $[19,20]$. However, a potential limitation of previous studies was the limited sample size. In this study, we analyzed c-Kit mutations in 139 metastatic OMM patients, which had the largest sample size to our knowledge. We found a higher mutation rate $(15.8 \%)$ than previously reported in Chinese patients $[15,33]$, probably because all the patients included in our study were metastatic OMM patients. We also found that c-Kit mutations were mainly located in exon 11 and 13 $(63.6 \%)$, which was similar to that of mucosal melanoma $[20,26]$.

In this study, we analyzed the clinical outcomes of metastatic OMMs patients who received conventional chemotherapy. The OS was decreased in $c$-Kit mutant patients in comparison with WT patients, and $c$-Kit mutation may act as a poor prognostic factor of metastatic OMMs. These results were consistent with previous findings [33].

Cell proliferation rate is an important prognostic factor of malignant tumors, and it can be regulated by 
Table 4: OS of WT and $c$-Kit mutant patients received chemotherapy

\begin{tabular}{|c|c|c|c|c|}
\hline \multirow{2}{*}{ Variable } & \multirow{2}{*}{ NO. } & \multirow{2}{*}{$\begin{array}{c}\text { Median OS } \\
\text { (weeks) }\end{array}$} & \multicolumn{2}{|c|}{$P$} \\
\hline & & & Unviariate & Multivariate \\
\hline \multicolumn{5}{|l|}{ Sex } \\
\hline Male & 68 & 32 & \multirow{2}{*}{0.846} & \multirow{2}{*}{-} \\
\hline Female & 59 & 32 & & \\
\hline \multicolumn{5}{|l|}{ Age, years } \\
\hline$<60$ & 56 & 30 & \multirow{2}{*}{0.845} & \multirow{2}{*}{-} \\
\hline$\geq 60$ & 71 & 33 & & \\
\hline \multicolumn{5}{|l|}{ Primary site } \\
\hline Palate & 77 & 32 & \multirow{4}{*}{0.546} & \multirow{4}{*}{-} \\
\hline Maxillary gum & 26 & 34 & & \\
\hline Mandible gum & 15 & 30 & & \\
\hline Other site & 9 & 35 & & \\
\hline \multicolumn{5}{|l|}{ ECOG PS score } \\
\hline 0 & 43 & 30 & \multirow{2}{*}{0.299} & \multirow{2}{*}{-} \\
\hline 1 & 84 & 33 & & \\
\hline \multicolumn{5}{|l|}{ Primary lesion } \\
\hline Positive & 20 & 26 & \multirow{2}{*}{$<0.001$} & \multirow{2}{*}{$<0.001$} \\
\hline Negative & 107 & 34 & & \\
\hline \multicolumn{5}{|l|}{ CLN } \\
\hline Positive & 23 & 27 & \multirow{2}{*}{$<0.001$} & \multirow{2}{*}{$<0.001$} \\
\hline Negative & 104 & 34 & & \\
\hline \multicolumn{5}{|l|}{ Site of metastases } \\
\hline Single site & 94 & 32 & \multirow{2}{*}{0.009} & \multirow{2}{*}{0.192} \\
\hline Multiple sites & 33 & 31 & & \\
\hline \multicolumn{5}{|l|}{$c$-Kit mutation } \\
\hline Positive (Group2) & 10 & 28 & \multirow{2}{*}{0.032} & \multirow{2}{*}{0.013} \\
\hline Negative (Group1) & 117 & 32 & & \\
\hline
\end{tabular}

KIT/MAPK/MEK signaling pathway [34]. We analyzed the cell proliferation rate by evaluating the expression of Ki67 in the primary tumor of metastatic OMM patients, because metastatic tumor tissues of these patients were rarely collected. The Ki67 expression increased significantly in $c$-Kit mutant patients compared with WT patients, indicating an increase in cell proliferation rate. Thus, $c$-Kit mutations may result in poor prognosis in metastatic OMMs through promoting cell proliferation. This, however, needs to be further addressed in future studies.

Imatinib, a c-Kit inhibitor, has been reported to have favorable outcomes in patients with metastatic gastrointestinal stromal tumors. In vitro studies have demonstrated the high sensitivity of $c$-Kit mutant cell lines to imatinib [35-37]. However, inconsistent results have also been reported in the treatment of melanomas with imatinib because of the different inclusion criteria of patients $[14,20]$. Therefore, whether imatinib is beneficial for metastatic OMM patients remains to be determined. In this study, we found that the OS of metastatic OMM patients received imatinib treatment was prolonged in comparison with patients received chemotherapy, which suggested that imatinib benefited metastatic OMM patients with $c$-Kit mutations, and c-Kit signaling could serve as a molecular therapeutic target in metastatic OMMs.

Although imatinib could act as a prognostic factor and a therapeutic target in metastatic OMMs, there 
are many factors influencing the effect of imatinib. Patients with $c$-Kit mutations in exon 11 (encodes the juxtamembrane domain) and exon 13 (encodes the tyrosine kinase domain) have been shown to benefit more from the imatinib treatment [26, 38-40]. In this study, we found that patients with $c$-Kit mutations in exon 11 and 13 had a shorter OS compared with patients with other mutations when they were treated with chemotherapy, but a longer OS when they were treated with imatinib. Thus, imatinib had different outcomes in treating different
c-Kit mutant subgroups. Furthermore, we found that there was no significant difference in OS between WT patients and imatinib-treated $c$-Kit mutations patients, which was consistent with other studies [41, 42]. This less-thanperfect result could be contributed to drug resistance of imatinib, which has been considered as a critical problem in treating patients with $c$-Kit mutations [43]. In our study, 5 out of 12 patients treated with imatinib showed obvious drug-resistant symptoms, which may reduce the efficacy of imatinib treatment. Thus, imatinib resistance should be
A

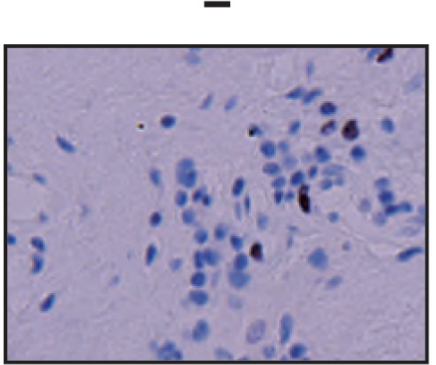

3

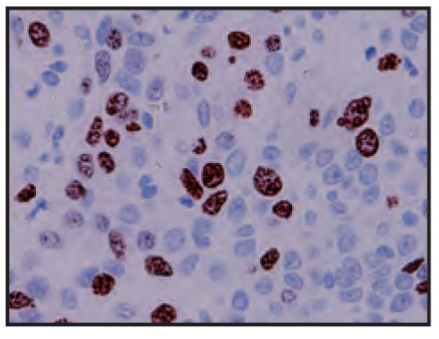

B
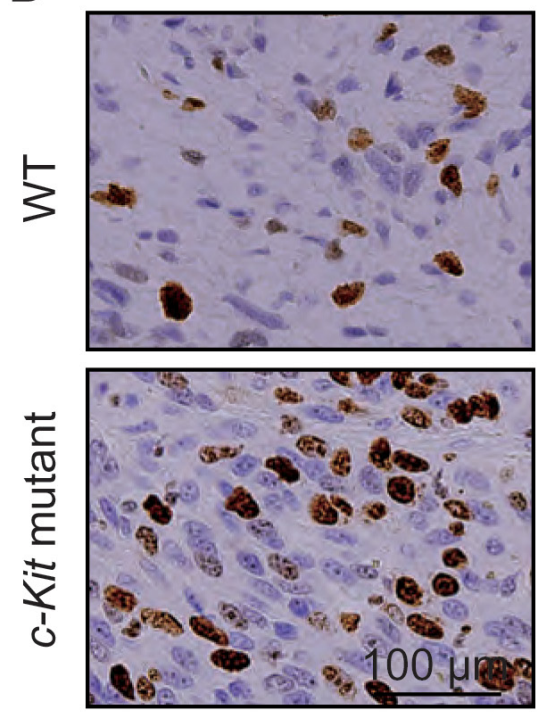

1

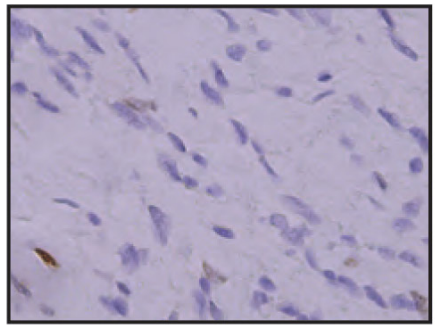

4

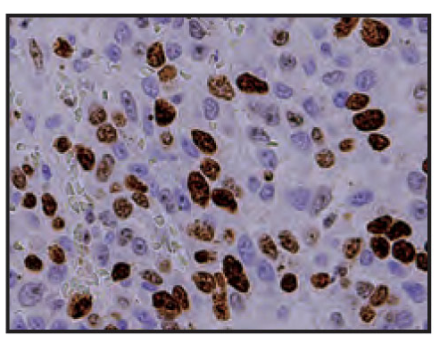

C

c

2

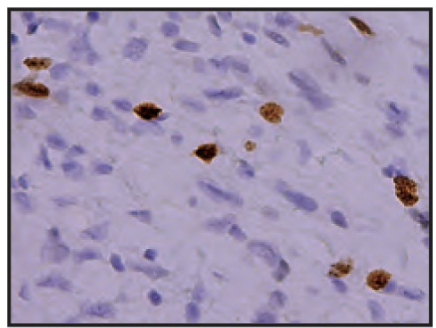

5

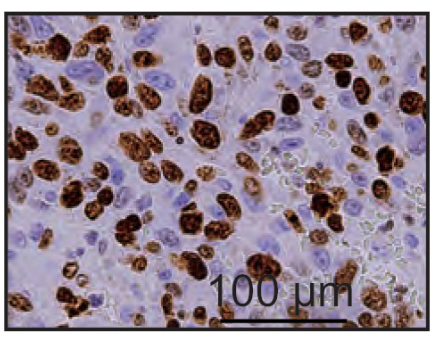

\begin{tabular}{c|c|c|c|c|c|c}
\hline & 1 & 2 & 3 & 4 & 5 & Total \\
\hline WT & 15 & 58 & 39 & 5 & 0 & 117 \\
c-Kit mutation & 0 & 2 & 7 & 11 & 2 & 22 \\
\hline
\end{tabular}

D

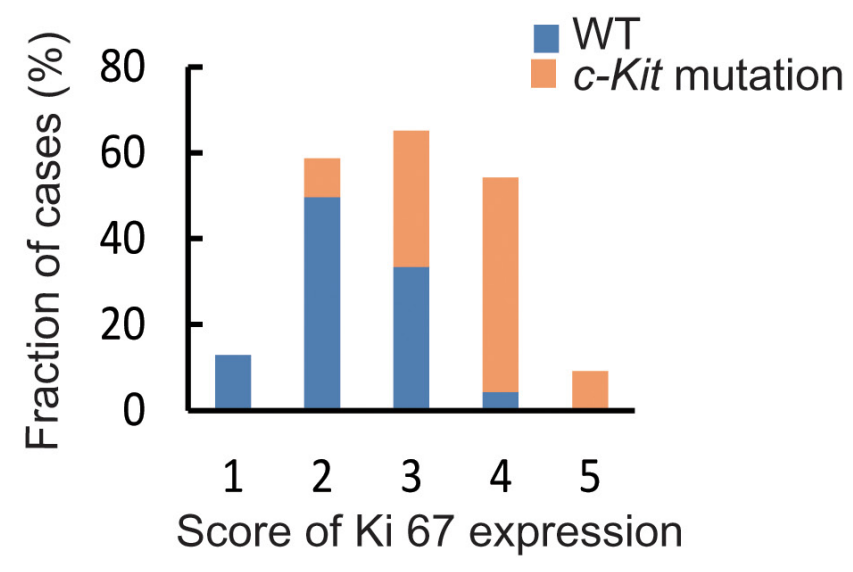

Figure 3: Thecorrelation of $\boldsymbol{c}$-Kit mutations with cell proliferation rate in OMMs. (A) Representative standard of Ki67 score. (B) Immunohistochemical staining of Ki67 in OMMs with WT and mutant c-Kit gene. (C) Table of Ki67 score in OMMs. (D) Bar diagram illustrating the Ki67 score in OMMs with WT (n=117) and mutant $c$-Kit gene $(\mathrm{n}=22)$. 
Table 5: OS of $c$-Kit mutant patients received chemotherapy and imatinib treatment

\begin{tabular}{|c|c|c|c|c|}
\hline \multirow{2}{*}{ Variable } & \multirow{2}{*}{ NO. } & \multirow{2}{*}{$\begin{array}{c}\text { Median OS } \\
\text { (weeks) }\end{array}$} & \multicolumn{2}{|c|}{$\boldsymbol{P}$} \\
\hline & & & Unviariate & Multivariate \\
\hline \multicolumn{5}{|l|}{ Sex } \\
\hline Male & 13 & 35 & \multirow{2}{*}{0.664} & \multirow{2}{*}{-} \\
\hline Female & 9 & 32 & & \\
\hline \multicolumn{5}{|l|}{ Age, years } \\
\hline$<60$ & 10 & 36 & \multirow{2}{*}{0.351} & \multirow{2}{*}{-} \\
\hline$\geq 60$ & 12 & 29 & & \\
\hline \multicolumn{5}{|l|}{ Primary site } \\
\hline Palate & 15 & 32 & \multirow{3}{*}{0.872} & \multirow{3}{*}{ - } \\
\hline Maxillary gum & 3 & 32 & & \\
\hline Mandible gum & 4 & 36 & & \\
\hline \multicolumn{5}{|l|}{ ECOG PS score } \\
\hline 0 & 8 & 32 & \multirow{2}{*}{0.578} & \multirow{2}{*}{-} \\
\hline 1 & 14 & 31 & & \\
\hline \multicolumn{5}{|l|}{ Primary lesion } \\
\hline Positive & 5 & 24 & \multirow{2}{*}{0.001} & \multirow{2}{*}{0.002} \\
\hline Negative & 17 & 36 & & \\
\hline \multicolumn{5}{|l|}{ CLN } \\
\hline Positive & 4 & 24 & \multirow{2}{*}{0.006} & \multirow{2}{*}{0.009} \\
\hline Negative & 18 & 36 & & \\
\hline \multicolumn{5}{|l|}{ Site of metastases } \\
\hline Single site & 16 & 35 & \multirow{2}{*}{0.027} & \multirow{2}{*}{0.207} \\
\hline Multiple sites & 6 & 26 & & \\
\hline \multicolumn{5}{|l|}{ Treatment strategy } \\
\hline Chemotherapy (Group2) & 10 & 28 & \multirow{2}{*}{0.004} & \multirow{2}{*}{$<0.001$} \\
\hline Imatinib (Group3) & 12 & 38 & & \\
\hline
\end{tabular}

A

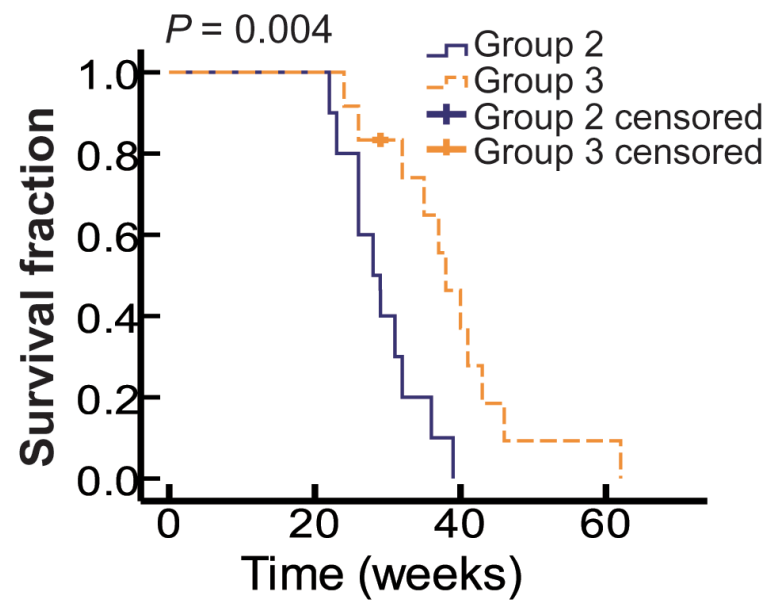

B

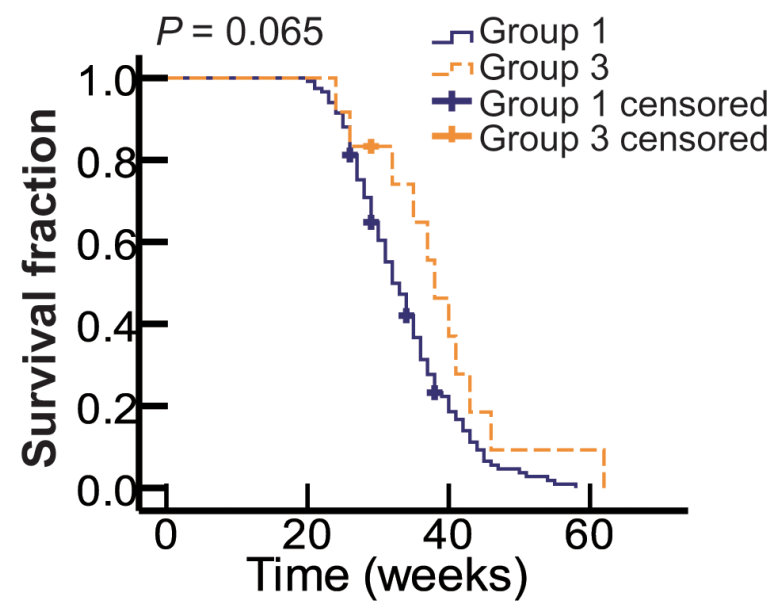

Figure 4: Imatinib increases OS of metastatic OMM patients with $\boldsymbol{c}$-Kit mutations. (A) Kaplan-Meier curves of OS of patients with $c$-Kit mutations received chemotherapy (Group2, solid blue line, $\mathrm{n}=10$ ) and imatinib treatment (Group3, dotted yellow line, $\mathrm{n}=12$ ). (B) Kaplan-Meier curves of OS of WT patients (Group1, solid blue line, $\mathrm{n}=117$ ) and $c$-Kit mutant patients received imatinib treatment (Group3, dotted yellow line, $\mathrm{n}=12$ ). 
taken into account and whether the combination of c-Kit inhibitor and chemotherapy could benefit patients with c-Kit mutations should be explored in future research.

\section{PATIENTS AND METHODS}

\section{Patients}

This study was approved by the Ethics Committee of Ninth People's Hospital affiliated to Shanghai Jiaotiong University School of Medicine and all patients were informed for this experimentation. The clinical manifestations, histopathology, treatment, and outcomes of OMM patients with distant metastasis hospitalized in our hospital from Jan. 2008 to Oct. 2015 were retrospectively analyzed. Patients with the following characteristics were eligible for the study: (1) primary OMMs histologically diagnosed by biopsy or surgery specimens by two experienced pathologists; (2) distant metastasis determined by radiological assessment; (3) complete clinical and follow-up records (per 3-6 months); (4) $c$-Kit mutant or wild-type tumors determined by gene screening; and (5) age $\leq 75$. Patients (1) with an Eastern Cooperative Oncology Group (ECOG) performance status score $\geq 2$ [44]; (2) brain metastasis and/or symptomatic central nervous system metastases; (3) treated by other methods, including radiotherapy; and (4) with other known gene mutations were excluded. The Supplementary Figure 2 showed the process of patients including of the present study. Finally, a total of 139 patients were included in this study.

\section{Treatment}

Upon the diagnosis of OMM, a radical resection of the primary lesion with at least $1.5 \mathrm{~cm}$ of healthy tissues was performed in all patients without distant metastasis; and a neck dissection was performed in patients diagnosed with positive CLN by physical exam and confirmed by ultrasound, CT scan, or/and PET CT. Patients were followed-up every 2-4 months for at least 5 years to monitor recurrence or/and metastasis. Once advanced distant metastasis was confirmed, the following treatment would be performed. Before Mar. 2012, for advanced OMM with distant metastasis, chemotherapy with DTIC (dacarbazine injection, Nanjing Pharmaceutical Co. Ltd., Jiangsu, China) and CDDP (cisplatin injection, Qilu Pharmaceutical Co. Ltd., Shandong, China) was repeated every 3 weeks for 4 circles. DTIC was administered on day 2-5 at a dose of $250 \mathrm{mg} / \mathrm{m}^{2}$, and CDDP was administered on day 1 at a dose of $75 \mathrm{mg} / \mathrm{m}^{2}$ (with hydration). After Mar. 2012, c-Kit mutations were screened, and imatinib treatment was recommended to patients with $c$-Kit mutations. For those patients who chose to accept imatinib treatment, imatinib was administered orally at a dose of $400 \mathrm{mg}$ once a day according to previous studies and a glass of water was recommend to minimize gastrointestinal irritation [26]. For those patients without $c$-Kit mutations or who refused imatinib treatment, chemotherapy with DTIC and CDDP described above was applied.

\section{Histology and immunohistochemistry}

The primary disease was diagnosed by biopsy and histology including hematoxylin-eosin staining and immunohistochemical staining of HMB-45, Melan-A, and S-100 protein. Immunohistochemical staining of Ki67, a widely used proliferation marker, was performed in the primary lesion as described previously [27, 45]. Sections were de-waxed and rehydrated, and $3 \% \mathrm{H}_{2} \mathrm{O}_{2}$ was used to fade melanin if necessary and block the activity of endogenous peroxidase. Antigen retrieval was performed by heat treating for $15 \mathrm{~min}$. Antibodies against HMB-45, Melan-A, S-100 and Ki67 (1: 200, Santa Cruz Biotechnology, Santa Cruz, CA, USA) were added and incubated overnight at $4^{\circ} \mathrm{C}$. The Dako Real Envision Detection System and AEC peroxidase substrate (Dako, Copenhagen, Denmark) were used to detect the primary antibody according to the manufacturer's instructions. To evaluate the nonspecific binding, the primary antibody was substituted with PBS. To evaluate the expression level of Ki67, the following score system was used: 1 for $<5 \%$ positive cells, 2 for $5-10 \%$ positive cells, 3 for $10-30 \%$ positive cells, 4 for $30-50 \%$ positive cells, and 5 for $>50 \%$ positive cells, respectively.

\section{Screening of gene mutations}

To select patients suitable for molecular treatment of Kit inhibitor, $c$-Kit mutations were screened in all patients diagnosed as distant metastatic OMMs after Mar. 2012 as described in previous studies [16, 26]. To analyze the effects of $c$-Kit mutations on the prognosis of distant metastatic OMMs, $c$-Kit mutations were screened in distant OMM patients who received chemotherapy from Jan. 2008 to Feb. 2012. To determinate $c$-Kit mutations, genomic DNA was extracted from paraffinembedded sections with a QIAamp DNA FFPE Tissue Kit (Qiagen, Hilden, Germany). To determinate hotspot mutations, exons 9, 11, 13, 17 and 18 of $c$-Kit gene were amplified by PCR with the genomic DNA. The PCR products were purified by using QIAquick (Qiagen) and directly sequenced with Big Dye Terminator sequencing chemistry on an ABI 3730 automated sequencer (Applied Biosystems, Foster City, CA). All mutations were confirmed by repeating bidirectional sequencing on the ABI sequencer.

\section{Prognostic variables}

The prognostic variables considered in this study included gender, age, primary site, ECOG score, the 
status and site of distant metastases, the status of CLNs, primary lesions and c-Kit mutations. "Primary lesions" indicated the lesions observed in the oral cavity during the treatment and follow-up period. The presence of residual primary lesion in distant metastatic OMMs could be due to patient's rejection of operation and unresectable lesions. "CLNs" indicated the status of metastasis of CLNs detected by physical exam and then confirmed by ultrasound, CT scan, or/and PET CT upon the diagnosis of distant metastasis. "Site of metastases" referred to the status and number of organ sites involved upon the diagnosis of distant metastasis. The specific organ sites at the time of metastasis were listed in the Supplementary Table 1.

\section{Statistical analysis}

All statistical analyses were performed with SPSS 16.0 for Windows (SPSS Inc., Chicago, IL). Differences between groups were analyzed using Student's t-test for continuous data, Fisher exact test and chi-square test for categorical data, and Mann-Whitney U test for ranked data, respectively. Survival curves were generated by the Kaplan-Meier method. The prognostic variables included gender, age, primary site, ECOG score, the status and site of distant metastases, CLNs, primary lesions and $c$-Kit mutations. The statistical significance of differences between survival curves was established by the Log-rank test, and multivariate analysis was performed with the Cox proportional hazard model. $P$ - values $<0.05$ were considered significant, and a $95 \%$ confidence interval was used in the Cox regression analysis. OS was defined as the time from the diagnosis of the first distant metastasis to death or the latest follow up.

\section{CONCLUSIONS}

Residual primary lesion, CLNs and $c$-Kit mutations act as adverse prognostic factors of metastatic OMMs. The Kit inhibitor imatinib could benefit metastatic OMM patients with $c$-Kit mutations. We highlight c-Kit as an important target in the research of molecular therapy.

\section{Author contributions}

W Guo and GX Ren designed the study. XH Ma, YT Wu, T Zhang, H Song, HY Jv collected and analysis the Data. XH Ma drafted the paper. All authors revised the final version of the manuscript.

\section{ACKNOWLEDGMENTS}

The authors thank Jiang Li and Ting Gu (Department of Oral Pathology, Ninth People's Hospital, School of Medicine, Shanghai Jiaotong University, China) for technical support.

\section{CONFLICTS OF INTEREST}

All author declare no conflicts of interest.

\section{FUNDING}

This work was supported by the Project of Science and Technology Commission of Shanghai Municipality [grant numbers: 10410711200, 08140902100, 11495802000, 14DZ1941400 and 14DZ1941402], The National Key Research and Development Program [grant number: 2016YFC0905003], The National Program on Key Research Project of China [No.2016YFC0902700, Precision Medicine] and Shanghai Health and Family Planning Commission [No.20154Y0057].

\section{REFERENCES}

1. Whiteman DC, Pavan WJ, Bastian BC. The melanomas: a synthesis of epidemiological, clinical, histopathological, genetic, and biological aspects, supporting distinct subtypes, causal pathways, and cells of origin. Pigment Cell Melanoma Res. 2011; 24:879-97. https://doi. org/10.1111/j.1755-148X.2011.00880.x.

2. Owens B. Melanoma. Nature. 2014; 515:S109. https://doi. org/10.1038/515S109a.

3. Haiducu ML, Hinek A, Astanehe A, Lee TK, Kalia S. Extracutaneous melanoma epidemiology in British Columbia. Melanoma Res. 2014; 24:377-80. https://doi. org/10.1097/cmr.0000000000000075.

4. Bishop KD, Olszewski AJ. Epidemiology and survival outcomes of ocular and mucosal melanomas: a populationbased analysis. Int J Cancer. 2014; 134:2961-71. https://doi. org/10.1002/ijc.28625.

5. Hicks MJ, Flaitz CM. Oral mucosal melanoma: epidemiology and pathobiology. Oral Oncol. 2000; 36:152-69.

6. Chang AE, Karnell LH, Menck HR. The National Cancer Data Base report on cutaneous and noncutaneous melanoma: a summary of 84,836 cases from the past decade. The American College of Surgeons Commission on Cancer and the American Cancer Society. Cancer. 1998; 83:1664-78.

7. Umeda M, Shimada K. Primary malignant melanoma of the oral cavity - its histological classification and treatment. $\mathrm{Br}$ J Oral Maxillofac Surg. 1994; 32:39-47.

8. Wu Y, Zhong Y, Li C, Song H, Guo W, Ren G. Neck dissection for oral mucosal melanoma: caution of nodular lesion. Oral Oncol. 2014; 50:319-24. https://doi. org/10.1016/j.oraloncology.2014.01.008.

9. Balch CM, Gershenwald JE, Soong SJ, Thompson JF, Atkins MB, Byrd DR, Buzaid AC, Cochran AJ, Coit DG, Ding S, Eggermont AM, Flaherty KT, Gimotty PA, et al. Final version of 2009 AJCC melanoma staging and 
classification. J Clin Oncol. 2009; 27:6199-206. https://doi. org/10.1200/JCO.2009.23.4799.

10. Agarwala SS. Current systemic therapy for metastatic melanoma. Expert Rev Anticancer Ther. 2009; 9:587-95. https://doi.org/10.1586/era.09.25.

11. Chapman PB, Einhorn LH, Meyers ML, Saxman S, Destro AN, Panageas KS, Begg CB, Agarwala SS, Schuchter LM, Ernstoff MS, Houghton AN, Kirkwood JM. Phase III multicenter randomized trial of the Dartmouth regimen versus dacarbazine in patients with metastatic melanoma. J Clin Oncol. 1999; 17:2745-51. https://doi.org/10.1200/ jco.1999.17.9.2745.

12. Middleton MR, Grob JJ, Aaronson N, Fierlbeck G, Tilgen W, Seiter S, Gore M, Aamdal S, Cebon J, Coates A, Dreno B, Henz M, Schadendorf D, et al. Randomized phase III study of temozolomide versus dacarbazine in the treatment of patients with advanced metastatic malignant melanoma. J Clin Oncol. 2000; 18:158-66. https://doi.org/10.1200/ JCO.2000.18.1.158.

13. Patel PM, Suciu S, Mortier L, Kruit WH, Robert C, Schadendorf D, Trefzer U, Punt CJ, Dummer R, Davidson N, Becker J, Conry R, Thompson JA, et al. Extended schedule, escalated dose temozolomide versus dacarbazine in stage IV melanoma: final results of a randomised phase III study (EORTC 18032). Eur J Cancer. 2011; 47:1476-83. https://doi.org/10.1016/j.ejca.2011.04.030.

14. Flaherty KT, Fisher DE. New strategies in metastatic melanoma: oncogene-defined taxonomy leads to therapeutic advances. Clin Cancer Res. 2011; 17:4922-8. https://doi. org/10.1158/1078-0432.ccr-10-2612.

15. Lyu J, Wu Y, Li C, Wang R, Song H, Ren G, Guo W. Mutation scanning of Braf, NRAS, KIT, and GNAQ/ GNA11 in oral mucosal melanoma: a study of 57 cases. J Oral Pathol Med. 2016; 45:295-301. https://doi.org/10.1111/ jop. 12358 .

16. Omholt K, Grafstrom E, Kanter-Lewensohn L, Hansson J, Ragnarsson-Olding BK. KIT pathway alterations in mucosal melanomas of the vulva and other sites. Clin Cancer Res. 2011; 17:3933-42. https://doi.org/10.1158/1078-0432. CCR-10-2917.

17. Houghton AN, Polsky D. Focus on melanoma. Cancer Cell. $2002 ; 2: 275-8$.

18. Chernoff KA, Bordone L, Horst B, Simon K, Twadell W, Lee K, Cohen JA, Wang S, Silvers DN, Brunner G, Celebi JT. GAB2 amplifications refine molecular classification of melanoma. Clin Cancer Res. 2009; 15:4288-91. https://doi. org/10.1158/1078-0432.CCR-09-0280.

19. Curtin JA, Busam K, Pinkel D, Bastian BC. Somatic activation of KIT in distinct subtypes of melanoma. J Clin Oncol. 2006; 24:4340-6. https://doi.org/10.1200/ JCO.2006.06.2984

20. Beadling C, Jacobson-Dunlop E, Hodi FS, Le C, Warrick A, Patterson J, Town A, Harlow A, Cruz F 3rd, Azar S, Rubin BP, Muller S, West R, et al. KIT gene mutations and copy number in melanoma subtypes. Clin Cancer Res. 2008; 14:6821-8. https://doi.org/10.1158/1078-0432. CCR-08-0575.

21. Mihajlovic M, Vlajkovic S, Jovanovic P, Stefanovic V. Primary mucosal melanomas: a comprehensive review. Int J Clin Exp Pathol. 2012; 5:739-53.

22. Yarden Y, Kuang WJ, Yang-Feng T, Coussens L, Munemitsu S, Dull TJ, Chen E, Schlessinger J, Francke U, Ullrich A. Human proto-oncogene c-Kit: a new cell surface receptor tyrosine kinase for an unidentified ligand. EMBO J. 1987; 6:3341-51.

23. Lennartsson J, Ronnstrand L. Stem cell factor receptor/ c-Kit: from basic science to clinical implications. Physiol Rev. 2012; 92:1619-49. https://doi.org/10.1152/ physrev.00046.2011.

24. Woodman SE, Davies MA. Targeting KIT in melanoma: a paradigm of molecular medicine and targeted therapeutics. Biochem Pharmacol. 2010; 80:568-74. https://doi. org/10.1016/j.bcp.2010.04.032.

25. Ali S, Ali S. Role of c-Kit/SCF in cause and treatment of gastrointestinal stromal tumors (GIST). Gene. 2007; 401:38-45. https://doi.org/10.1016/j.gene.2007.06.017.

26. Guo J, Si L, Kong Y, Flaherty KT, Xu X, Zhu Y, Corless CL, Li L, Li H, Sheng X, Cui C, Chi Z, Li S, et al. Phase II, open-label, single-arm trial of imatinib mesylate in patients with metastatic melanoma harboring c-Kit mutation or amplification. J Clin Oncol. 2011; 29:2904-9. https://doi. org/10.1200/jco.2010.33.9275.

27. Henrique R, Azevedo R, Bento MJ, Domingues JC, Silva $\mathrm{C}$, Jeronimo C. Prognostic value of Ki-67 expression in localized cutaneous malignant melanoma. J Am Acad Dermatol. 2000; 43:991-1000. https://doi.org/10.1067/ mjd.2000.109282.

28. Smalley KS, Sondak VK, Weber JS. c-KIT signaling as the driving oncogenic event in sub-groups of melanomas. Histol Histopathol. 2009; 24:643-50.

29. Lazarev S, Gupta V, Hu K, Harrison LB, Bakst R. Mucosal melanoma of the head and neck: a systematic review of the literature. Int J Radiat Oncol Biol Phys. 2014; 90:1108-18. https://doi.org/10.1016/j.ijrobp.2014.03.042.

30. Lopez F, Rodrigo JP, Cardesa A, Triantafyllou A, Devaney KO, Mendenhall WM, Haigentz M Jr, Strojan P, Pellitteri PK, Bradford CR, Shaha AR, Hunt JL, de Bree R, et al. Update on primary head and neck mucosal melanoma. Head Neck. 2016; 38:147-55. https://doi.org/10.1002/hed.23872.

31. Keller DS, Thomay AA, Gaughan J, Olszanski A, Wu H, Berger AC, Farma JM. Outcomes in patients with mucosal melanomas. J Surg Oncol. 2013; 108:516-20. https://doi. org/10.1002/jso.23445.

32. Postow MA, Hamid O, Carvajal RD. Mucosal melanoma: pathogenesis, clinical behavior, and management. Curr Oncol Rep. 2012; 14:441-8. https://doi.org/10.1007/ s11912-012-0244-x. 
33. Kong Y, Si L, Zhu Y, Xu X, Corless CL, Flaherty KT, Li L, Li H, Sheng X, Cui C, Chi Z, Li S, Han M, et al. Largescale analysis of KIT aberrations in Chinese patients with melanoma. Clin Cancer Res. 2011; 17:1684-91. https://doi. org/10.1158/1078-0432.CCR-10-2346.

34. Todd JR, Scurr LL, Becker TM, Kefford RF, Rizos H. The MAPK pathway functions as a redundant survival signal that reinforces the PI3K cascade in c-Kit mutant melanoma. Oncogene. 2014; 33:236-45. https://doi.org/10.1038/ onc. 2012.562

35. Ashida A, Takata M, Murata H, Kido K, Saida T. Pathological activation of KIT in metastatic tumors of acral and mucosal melanomas. Int J Cancer. 2009; 124:862-8. https://doi.org/10.1002/ijc.24048.

36. Antonescu CR, Busam KJ, Francone TD, Wong GC, Guo T, Agaram NP, Besmer P, Jungbluth A, Gimbel M, Chen CT, Veach D, Clarkson BD, Paty PB, et al. L576P KIT mutation in anal melanomas correlates with KIT protein expression and is sensitive to specific kinase inhibition. Int J Cancer. 2007; 121:257-64. https://doi.org/10.1002/ijc.22681.

37. Jiang X, Zhou J, Yuen NK, Corless CL, Heinrich MC, Fletcher JA, Demetri GD, Widlund HR, Fisher DE, Hodi FS. Imatinib targeting of KIT-mutant oncoprotein in melanoma. Clin Cancer Res. 2008; 14:7726-32. https://doi. org/10.1158/1078-0432.CCR-08-1144.

38. Hodi FS, Friedlander P, Corless CL, Heinrich MC, Mac Rae S, Kruse A, Jagannathan J, Van den Abbeele AD, Velazquez EF, Demetri GD, Fisher DE. Major response to imatinib mesylate in KIT-mutated melanoma. J Clin Oncol. 2008; 26:2046-51. https://doi.org/10.1200/JCO.2007.14.0707.

39. Lutzky J, Bauer J, Bastian BC. Dose-dependent, complete response to imatinib of a metastatic mucosal melanoma with a K642E KIT mutation. Pigment Cell Melanoma Res. 2008; 21:492-3. https://doi. org/10.1111/j.1755-148X.2008.00475.x.
40. Carvajal RD, Antonescu CR, Wolchok JD, Chapman PB, Roman RA, Teitcher J, Panageas KS, Busam KJ, Chmielowski B, Lutzky J, Pavlick AC, Fusco A, Cane L, et al. KIT as a therapeutic target in metastatic melanoma. JAMA. 2011; 305:2327-34. https://doi.org/10.1001/ jama.2011.746.

41. Kim KB, Eton O, Davis DW, Frazier ML, McConkey DJ, Diwan AH, Papadopoulos NE, Bedikian AY, Camacho LH, Ross MI, Cormier JN, Gershenwald JE, Lee JE, et al. Phase II trial of imatinib mesylate in patients with metastatic melanoma. Br J Cancer. 2008; 99:734-40. https://doi. org/10.1038/sj.bjc.6604482.

42. Wyman K, Atkins MB, Prieto V, Eton O, McDermott DF, Hubbard F, Byrnes C, Sanders K, Sosman JA. Multicenter Phase II trial of high-dose imatinib mesylate in metastatic melanoma: significant toxicity with no clinical efficacy. Cancer. 2006; 106:2005-11. https://doi.org/10.1002/ cncr. 21834.

43. Demetri GD, Reichardt P, Kang YK, Blay JY, Rutkowski P, Gelderblom H, Hohenberger P, Leahy M, von Mehren M, Joensuu H, Badalamenti G, Blackstein M, Le Cesne A, et al. Efficacy and safety of regorafenib for advanced gastrointestinal stromal tumours after failure of imatinib and sunitinib (GRID): an international, multicentre, randomised, placebo-controlled, phase 3 trial. Lancet. 2013; 381:295302. https://doi.org/10.1016/S0140-6736(12)61857-1.

44. Oken MM, Creech RH, Tormey DC, Horton J, Davis TE, McFadden ET, Carbone PP. Toxicity and response criteria of the Eastern Cooperative Oncology Group. Am J Clin Oncol. 1982; 5:649-55.

45. Song $\mathrm{H}, \mathrm{Wu} \mathrm{Y}$, Ren G, Guo W, Wang L. Prognostic factors of oral mucosal melanoma: histopathological analysis in a retrospective cohort of 82 cases. Histopathology. 2015; 67:548-56. https://doi.org/10.1111/his.12692. 